BMJ Paediatrics Open

\title{
Consent and recruitment: the reporting of paediatric trials published in 2012
}

Allison Gates, ${ }^{1,2}$ Patrina Caldwell, ${ }^{3}$ Sarah Curtis, ${ }^{2}$ Leonila Dans, ${ }^{4}$ Ricardo M Fernandes, ${ }^{5,6}$ Lisa Hartling, ${ }^{1,2}$ Lauren E Kelly, ${ }^{7,8}$ Katrina Williams, ${ }^{9,10,11}$ Kerry Woolfall, ${ }^{12}$ Michele P Dyson ${ }^{1,2}$

\section{ABSTRACT}

Objectives We evaluated 300 paediatric trials to determine: the consent and recruitment strategies used, who trial information was targeted to, how incentives were used and if they achieved their recruitment targets.

Methods For this cross-sectional evaluation, we searched the Cochrane Central Register of Controlled Trials for paediatric trials published in 2012 and randomly selected 300 that reported on outcomes for participants aged $\leq 21$ years. We collected data on consent and recruitment procedures for each trial and undertook descriptive analyses in SPSS statistics V.23.

Results All but one trial (99.7\%) used a standard recruitment strategy. Most (92\%) trials reported that consent was obtained but only $13 \%$ reported who obtained consent. Two-thirds (65\%) of trials included schoolaged participants, and of these $68 \%$ reported obtaining assent. Half $(50 \%)$ of the trials reported who the trial information was targeted to. Most trials (75\%) of schoolaged participants targeted information towards children or children and their parents. Fourteen per cent of trials reported using incentives, half $(50 \%)$ of which were in the form of compensation. Only $48 \%$ of trials reported sufficient data to determine if their recruitment targets were achieved. Of these, $70 \%$ achieved their targets.

Conclusions Notable reporting shortcomings included: how families were recruited into the trial, who obtained consent and/or assent and how, who trial information was directed to, whether incentives were used and sufficient data to determine if the recruitment target was achieved. Forthcoming paediatric-specific reporting standards may improve reporting in this priority area. Our data provide a baseline for ongoing monitoring of the state of the research.

\section{INTRODUCTION}

In 2012, Standards for Research in (StaR)

\section{(C) Author(s) (or their} employer(s)) 2018. Re-use permitted under CC BY-NC. No commercial re-use. See rights and permissions. Published by BMJ

For numbered affiliations see end of article.

Correspondence to Dr Allison Gates; agates1@ ualberta.ca
Child Health published six evidence-based standards to guide the rigorous design, conduct and reporting of paediatric trials. ${ }^{12}$ Each standard ${ }^{3-8}$ includes practice recommendations and a research agenda to address knowledge gaps. To characterise the state of the literature, we analysed a random sample of 300 paediatric trials published in $2012^{9}$ and identified various shortcomings in their conduct and reporting. Among other

\section{What is already known on this topic?}

In 2012, Standards for Research in Child Health published evidence-based guidance to inform ethically sound recruitment and consent in paediatric trials, and identified knowledge gaps.

- To optimise the value of children's participation in research, trialists must safeguard them from avoidable harm, use rigorous methodologies and report their findings transparently.

\section{What this study hopes to add?}

Reporting shortcomings included: how families were recruited, who obtained consent/assent, who trial information was directed to, whether incentives were used, if recruitment targets were reached.

- The data from this study will serve as a baseline for ongoing monitoring and evaluation of the state of the research.

issues, most trials reported results that were at unclear or high risk of bias, and only $46 \%$ were registered in a clinical trial registry. ${ }^{9}$

Trialists are ethically obligated to optimise the value of children's participation in research by safeguarding them from avoidable harms, ${ }^{10} 11$ using rigorous methodologies $^{12}$ and reporting their findings transparently. ${ }^{13}$ Ethically sound recruitment and consent procedures include: obtaining consent from parents and assent from children, approaching all eligible children and not unfairly excluding any children, providing families with age-appropriate trial information, ensuring that incentives do not influence children's decision-making and clearly differentiating between elements of standard care and those that are part of the trial. ${ }^{3}$ Safeguarding children from avoidable harm also includes carefully planned recruitment targets. Trials that recruit too many participants needlessly expose children to the burdens of research participation, while 
those that are underpowered to detect clinically meaningful effects contribute to research waste. ${ }^{14}$

In response to the knowledge gaps and priorities identified by the Consent and Recruitment Standard Development Group, we evaluated the consent and recruitment procedures for 300 paediatric trials to determine: the consent and recruitment strategies used, who trial information was targeted to, how incentives were used and whether they achieved their recruitment targets.

\section{METHODS}

\section{Context}

The analyses presented herein are part of a larger study ${ }^{915}$ in which we characterised the conduct and reporting qualities of 300 paediatric trials published in 2012. A full description of the study methods appears in a previous publication. ${ }^{9}$

\section{Database search}

In November 2013, a research librarian searched the Cochrane Central Register of Controlled Trials (CENTRAL) for randomised trials published in 2012 (online supplementary file 1). CENTRAL is a comprehensive database of reports of randomised and quasi-randomised trials, taken mainly from MEDLINE and Embase. ${ }^{16}$ The 2012 publication date coincided with the publication of the StaR Child Health Standards.

\section{Trial selection}

A total of 2296 unique records were identified via the search. We ordered these randomly in Excel (V.2016; Microsoft, Redmond, Washington, USA) and selected the first 300 published trials that: (a) recruited participants aged 0-18 years or (b) recruited both children and adults with an upper age limit of 21 years. The inclusion criteria were selected to match those used by Cochrane Child Health to select trials for their trials register (which originate from CENTRAL).${ }^{17}$ The sample size coincides with our previous evaluation of paediatric trials published in $2007 .{ }^{15}$ The sample was not restricted by language, condition, intervention or outcome type.

\section{Data extraction}

For each included trial, we extracted data into Research Electronic Data Capture ${ }^{18}$ pertaining to the characteristics of the: publication, trial design, intervention, trial conduct, trial sample, data monitoring committee and follow-up, outcomes and conclusions, risk of bias and trial registration and protocol. ${ }^{9}$ We also collected additional data to address the knowledge gaps and priorities outlined by the Standard Development Groups. An author (AG or MPD) verified the extracted data to identify errors or omissions.

The data extraction guide for the variables included in this report is in online supplementary file 2 . The primary diagnostic category was classified according to the WHO's International Statistical Classification of Diseases and Related Health Problems 10th Revision. ${ }^{19}$ Participants' recruitment location was classified according to the World Bank income classification for the 2019 fiscal year. ${ }^{20}$ The recruitment strategy was classified as standard if the participants provided consent and were then randomised in a typical manner (eg, 1:1, 1:2). The reasons for recruitment delays were classified based on the definitions provided by Kaur et al. ${ }^{21}$ Incentives were categorised as one or more of the following: reimbursements (costs associated with participation that are paid back, eg, parking, travel), compensation (participants are paid a modest amount for their time and effort), tokens of appreciation (a small gift given at the end of the trial, usually not known beforehand) and incentive payments (typically known before participation and used to enhance recruitment). Children were considered to be of 'school age' if they were $>5$ years old. Participants were considered 'mature minors' if they were adolescents or young adults aged $\geq 12$ years. Whether children with chronic or comorbid conditions were excluded was collected to estimate if children were fairly and equitably recruited into the trial.

We referred to protocols, trial registries and associated publications to complement data extraction. Trial registers were sought via the International Clinical Trials Registry Platform, the International Standard Randomised Controlled Trials Number (ISRCTN) Registry and Google. Trial registers were located for $46 \%(n=138 / 300)$ of the trials. ${ }^{9}$ Protocols or companion articles were used only when cited in the publications. Authors were not contacted to collect consent and recruitment details beyond those in published reports.

\section{Data analysis}

The data were exported to an Excel workbook for cleaning and to SPSS Statistics V.23 (IBM, Armonk, New York, USA) for descriptive analysis. To determine whether the recruitment target was reached, the result of the sample size calculation was compared with the number of participants enrolled in the trial. The data on the use of incentives were stratified by continent because allowable incentives for paediatric research vary by region (eg, the European Union advocates banning all incentive payments for children, while incentive payments for children participating in trials are relatively common in the USA). ${ }^{10}$

\section{RESULTS}

\section{Patient population and consent and recruitment procedures}

Most trials recruited from high-income countries ${ }^{20}$ $(\mathrm{n}=202 / 300,67 \%)$ and $68 \% \quad(\mathrm{n}=205 / 300)$ reported excluding patients with comorbid or chronic diseases (table 1$)$. Only one trial $(n=1 / 300,0.3 \%)$ reported using a non-standard recruitment strategy (Zelen's design, whereby participants are randomly allocated to treatment before seeking consent; participants can accept or decline the intervention offered). Only one trial 
Table 1 Characteristics of the patient populations and recruitment approaches $(n=300)$

\begin{tabular}{lc}
\hline Characteristic & $\mathbf{n ~ ( \% )}$ \\
\hline Recruitment location & \\
\hline Low-income country & $16(5.3)$ \\
\hline Lower-middle-income country & $33(11.0)$ \\
Upper-middle-income country & $56(18.7)$ \\
\hline High-income country & $202(67.3)$
\end{tabular}

Exclusion of patients with chronic diseases

\begin{tabular}{lr|}
\hline Yes & $205(68.3)$ \\
\hline No & $59(19.7)$ \\
\hline Unclear & $36(12.0)$ \\
\hline Recruitment strategy & $299(99.7)$ \\
\hline Standard & $1(0.3)$ \\
\hline Not standard & $1(0.3)$ \\
\hline $\begin{array}{l}\text { Time to decide whether to enrol } \\
\text { Limited }\end{array}$ & $299(99.7)$ \\
\hline Not reported & $8(2.7)$ \\
\hline $\begin{array}{l}\text { Who first approached the patient } \\
\text { Child's clinician }\end{array}$ & $28(9.3)$ \\
\hline $\begin{array}{l}\text { Researcher or clinician unknown to } \\
\text { patient }\end{array}$ & $15(5.0)$ \\
\hline Other & $249(83.0)$ \\
\hline Not reported & $275(91.7)$ \\
\hline Consent obtained and reported & $25(8.3)$ \\
\hline Yes &
\end{tabular}

Who obtained consent

$\begin{array}{lc}\text { Child's clinician } & 2(0.7) \\ \begin{array}{l}\text { Researcher or clinician unknown to } \\ \text { patient }\end{array} & 31(10.3)\end{array}$

\begin{tabular}{lc}
\hline Other & $6(2.0)$ \\
\hline Not reported & $261(87.0)$ \\
\hline $\begin{array}{l}\text { How consent was provided } \\
\text { Parental permission }\end{array}$ & $149(49.7)$ \\
\hline $\begin{array}{l}\text { Parental permission and participant } \\
\text { assent }\end{array}$ & $117(39.0)$ \\
\hline Consent of a mature minor & $4(1.3)$ \\
\hline Not reported & $30(10.0)$ \\
\hline Patients/families involved in trial design/conduct \\
\hline Reported & $9(3.0)$ \\
\hline Not reported & $291(97.0)$ \\
\hline Source of recruitment† & $74(24.7)$ \\
\hline Inpatients & $51(17.0)$ \\
\hline Outpatients & $38(12.7)$ \\
\hline Clinician's office & $70(23.3)$ \\
\hline School & $44(14.7)$ \\
\hline Community
\end{tabular}

Continued

\begin{tabular}{|c|c|}
\hline Characteristic & n (\%) \\
\hline Other & $14(4.7)$ \\
\hline Unclear or not reported & $56(18.7)$ \\
\hline \multicolumn{2}{|l|}{ Primary diagnostic category $\ddagger$} \\
\hline Mental and behavioural disorders & $50(16.7)$ \\
\hline Infectious and parasitic disease & $39(13.0)$ \\
\hline Respiratory system & $30(10.0)$ \\
\hline $\begin{array}{l}\text { Conditions originating in the perinatal } \\
\text { period }\end{array}$ & $28(9.3)$ \\
\hline $\begin{array}{l}\text { Endocrine, nutritional and metabolic } \\
\text { diseases }\end{array}$ & $25(8.3)$ \\
\hline Oral health & $19(6.3)$ \\
\hline $\begin{array}{l}\text { Factors influencing health status and } \\
\text { contact with health services }\end{array}$ & $13(4.3)$ \\
\hline Digestive system & $10(3.3)$ \\
\hline $\begin{array}{l}\text { Blood, blood forming organs and } \\
\text { immune mechanism }\end{array}$ & $7(2.3)$ \\
\hline $\begin{array}{l}\text { Congenital malformations, deformations } \\
\text { and chromosomal abnormalities }\end{array}$ & $7(2.3)$ \\
\hline Nervous system & $7(2.3)$ \\
\hline Eye and adnexa & $5(1.7)$ \\
\hline Ear and mastoid process & $4(1.3)$ \\
\hline $\begin{array}{l}\text { Injury, poisoning and consequences of } \\
\text { external causes }\end{array}$ & $4(1.3)$ \\
\hline Circulatory system & $3(1.0)$ \\
\hline $\begin{array}{l}\text { External causes of morbidity and } \\
\text { mortality }\end{array}$ & $3(1.0)$ \\
\hline Genitourinary system & $3(1.0)$ \\
\hline $\begin{array}{l}\text { Musculoskeletal system and connective } \\
\text { tissue }\end{array}$ & $3(1.0)$ \\
\hline Neoplasms & $3(1.0)$ \\
\hline $\begin{array}{l}\text { Pregnancy, childbirth and the } \\
\text { puerperium }\end{array}$ & $2(0.7)$ \\
\hline Skin and subcutaneous tissue & $2(0.7)$ \\
\hline Other & $33(11.0)$ \\
\hline
\end{tabular}

*Defined according to the World Bank income classification, 2019 fiscal year. ${ }^{20}$ Some trials recruited from more than one category. †Total exceeds 300 because some trials reported multiple sources. ¥Defined according to the International Statistical Classification of Diseases and Related Health Problems 10th Revision (2010). ${ }^{18}$ These data have been previously reported, but are shown here for context. $^{9}$

$(\mathrm{n}=1 / 300,0.3 \%)$ reported a specified amount of time (7 days) for participants to decide whether to enrol. Seventeen per cent $(n=51 / 300)$ of trials reported who first spoke to the family about participating. The most common point of contact was a researcher or clinician unknown to the participant $(\mathrm{n}=28 / 51,55 \%)$.

Who trial information was targeted to

Most trials reported that consent was obtained $(n=275 / 300,92 \%)$, but only $13 \%(n=39 / 300)$ reported 


\begin{tabular}{lc}
$\begin{array}{l}\text { Table } 2 \\
\text { participants and families }(\mathrm{n}=300)\end{array}$ \\
\hline Characteristic & $\mathbf{n}(\%)$ \\
\hline How the family heard about the trial & \\
\hline Approached during healthcare visit & $108(36.0)$ \\
\hline Mailing & $15(5.0)$ \\
Generalised mailing & $4(1.3)$ \\
\hline Targeted mailing & $9(3.0)$ \\
\hline Personalised mailing & $2(0.7)$ \\
\hline Phone calls & $7(2.3)$ \\
\hline Media & $26(8.7)$ \\
\hline Pamphlets & $20(6.7)$ \\
\hline Other & $63(21.0)$ \\
\hline Not reported & $116(38.7)$ \\
\hline Who trial information was targeted to & $88(29.3)$ \\
\hline Parents & $7(2.3)$ \\
\hline Mature minors & $56(18.7)$ \\
\hline Parents and children & $149(49.7)$ \\
\hline Not reported &
\end{tabular}

*Some trials used multiple approaches.

who obtained consent. Ninety per cent $(n=270 / 300)$ of trials reported how consent was provided. Among these, $55 \%(\mathrm{n}=149 / 270)$ obtained consent via parental permission and $43 \%(\mathrm{n}=117 / 270)$ via parental permission combined with participant assent. Four trials (2\%) reported only obtaining the consent of a mature minor. These included trials of the following: corrective exercises for scoliosis, prevention of acute knee injuries in athletes, bright-light therapy for non-seasonal depression and oxidant and antioxidant levels in patients with orthodontic tooth movement. Of trials that included schoolaged participants ( $>5$ years old; $\mathrm{n}=196 / 300,65 \%$ ), $68 \%$ $(\mathrm{n}=117 / 172)$ reported obtaining participant assent and $32 \%(\mathrm{n}=55 / 172)$ reported obtaining parental permission only. Three per cent $(n=9 / 300)$ of trials reported that participants and families were involved in the design or conduct of the trial.

Nineteen per cent $(n=56 / 300)$ of trials did not report the recruitment setting (or it was unclear). When clearly reported, most often trials recruited participants from inpatient populations $(\mathrm{n}=74 / 300,25 \%)$, outpatient populations $(n=51 / 300,17 \%)$ or schools $(n=70 / 300$, $23 \%$ ).

About two-thirds $(\mathrm{n}=184 / 300,61 \%)$ of trials reported how families were informed about the opportunity to participate (table 2). Of these, 59\% ( $\mathrm{n}=108 / 184)$ reported that parents were approached during a healthcare visit, $8 \%(\mathrm{n}=15 / 184)$ used mail invites, $4 \%(\mathrm{n}=7 / 184)$ approached parents by telephone, 14\% (n=26/184) used media messages (eg, via the radio, newspaper or a website $)$ and $11 \%(n=20 / 184)$ used pamphlets. Other methods $(n=63 / 184,34 \%)$ included schools (ie, school staff contacted parents about the trial), community contacts and word of mouth; and identifying potential participants through chart reviews or previous trials. Sixteen per cent $(n=30 / 184)$ of trials used multiple means of informing families about the opportunity to participate.

Half $(n=151 / 300,50 \%)$ of the trials reported the person who was the target of the trial information. Of these, $58 \%(n=88 / 151)$ targeted the information towards parents only, $5 \%(\mathrm{n}=7 / 151)$ towards mature minors only and $37 \% \quad(\mathrm{n}=56 / 151)$ towards parents and children. Although it was not reported, we assumed that an additional 13\% ( $n=40 / 300)$ intended the information to be for parents, as participants were infants or children less than school age. When it was reported, all trials that included only participants $\leq 5$ years of age directed the information to parents only $(\mathrm{n}=64 / 64,100 \%)$. Most trials $(\mathrm{n}=65 / 87,75 \%)$ that included participants $>5$ years of age directed trial information either to mature minors only or both parents and children.

\section{Use of incentives}

Most trials did not report whether incentives were used $(\mathrm{n}=253 / 300,84 \%)$ and five $(2 \%)$ reported not using incentives. Fourteen per cent $(n=42 / 300)$ of trials reported using incentives. These were most often in the form of compensation $(n=21 / 42,50 \%)$ and tokens of appreciation ( $\mathrm{n}=12 / 42,29 \%)$ (five studies (12\%) provided reimbursements and seven $(17 \%)$ provided incentive payments). Reported compensation amounts varied, for example, free dental care and $\$ 20$ for families participating in a 5-year dental amalgam trial; $\$ 5-\$ 10$ gift cards for adolescents participating in a trial of telephone-based preventive health education and counselling. Tokens of appreciation also varied, for example, an insecticide impregnated bed net and soap for families participating in a trial of therapeutic food for catch-up growth after malaria; $\$ 40$ for teachers participating in a trial of a school-based intervention. Tables 3 and 4 show the reported incentive use and types of incentives used stratified by continent of recruitment. The use

Table 3 Use of incentives stratified by recruitment continent $(n=300)^{*}$

\begin{tabular}{lrccc}
\hline & & \multicolumn{2}{l}{ Use of incentives, $\mathbf{n}(\%)$} \\
\cline { 3 - 5 } $\begin{array}{l}\text { Recruitment } \\
\text { continent }\end{array}$ & N & Yes & No & $\begin{array}{l}\text { Not } \\
\text { reported }\end{array}$ \\
\hline Africa & 26 & $3(11.5)$ & $1(3.8)$ & $22(84.6)$ \\
\hline Asia & 82 & $1(1.2)$ & $2(2.4)$ & $79(96.3)$ \\
Australia & 18 & $3(16.7)$ & $0(0.0)$ & $15(83.3)$ \\
Europe & 54 & $2(3.7)$ & $3(5.6)$ & $49(90.7)$ \\
North America & 119 & $33(27.7)$ & $0(0.0)$ & $86(72.3)$ \\
South America & 9 & $0(0.0)$ & $0(0.0)$ & $9(100.0)$
\end{tabular}

*Some studies recruited participants from more than one continent. 
Table 4 Types of incentives used stratified by continent $(n=42)^{*}$

\begin{tabular}{|c|c|c|c|c|c|}
\hline \multirow[b]{2}{*}{ Recruitment continent } & \multirow[b]{2}{*}{$\mathbf{N}$} & \multicolumn{4}{|c|}{ Types of incentives used, n (\%) } \\
\hline & & Compensation & Tokens of appreciation & Reimbursements & Payments \\
\hline Africa & 3 & $2(66.7)$ & $1(33.3)$ & $1(33.3)$ & $0(0.0)$ \\
\hline Asia & 1 & $0(0.0)$ & $1(100.0)$ & $0(0.0)$ & $0(0.0)$ \\
\hline Australia & 3 & $1(33.3)$ & $0(0.0)$ & $2(66.7)$ & $0(0.0)$ \\
\hline Europe & 2 & $2(100.0)$ & $0(0.0)$ & $0(0.0)$ & $0(0.0)$ \\
\hline North America & 33 & $16(48.5)$ & $10(30.3)$ & $2(6.1)$ & 7 (21.2) \\
\hline South America & 0 & $0(0.0)$ & $0(0.0)$ & $0(0.0)$ & $0(0.0)$ \\
\hline
\end{tabular}

*Some studies offered multiple types of incentives.

of incentives was most often reported in studies that recruited from North America $(n=33 / 119,28 \%)$. All studies that offered incentive payments recruited from North America.

The child was often the recipient of the incentive, rather than the parents or family: $20 \%(n=1 / 5)$ of reimbursements (eg, $\$ 5$ for a bus ticket for travel), $48 \%(n=10 / 21)$ of compensation incentives (eg, \$10 for completing a survey), $50 \%(\mathrm{n}=6 / 12)$ of tokens of appreciation ( $\mathrm{eg}, \$ 10$ gift certificate), and $83 \%(\mathrm{n}=5 / 6)$ of incentive payments (eg, \$50 supermarket gift cards) were intended for the participant.

\section{Recruitment target attainment}

About half ( $n=145 / 300,48 \%)$ of the trials reported sufficient information to determine if the recruitment target was achieved (table 5). Of these, 70\% ( $\mathrm{n}=102 / 145)$ recruited their target sample size. Of the studies that recruited their target sample size, four (3.9\%) reported using incentives and three $(2.9 \%)$ explicitly reported not using incentives.

Recruitment delays were reported in $6 \%(n=19 / 300)$ of trials and were most often due to patient-level $(n=10 / 19$, $53 \%$; eg, travel, duration of trial, preferences) or triallevel factors $(n=9 / 19,47 \%$; eg, funding, trial management, feasibility). Strategies to address recruitment delays included stopping the trial before the recruitment target was achieved $(n=13 / 19,68 \%)$, extending the recruitment period $(n=3 / 19,16 \%)$, adding trial sites $(n=2 / 19$, $11 \%)$, modifying the eligibility criteria $(n=3 / 19,16 \%)$ and modifying the incentives $(\mathrm{n}=1 / 19,5 \%)$.

\section{DISCUSSION}

This study addresses some of the knowledge gaps and priorities identified by StaR Child Health's Consent and Recruitment Standard Development Group. ${ }^{3}$ We found that details of consent and recruitment procedures were infrequently reported within publications of paediatric trials. Although most trials reported obtaining consent, elaboration on the consent and recruitment process was not common. Our previous evaluation of risk of bias and trial registration among the same sample of trials and comparison with trials published in 2007 showed that some aspects of trial reporting had improved over time (eg, reporting of allocation concealment improved and trial registration doubled). Because the trials evaluated herein were undertaken before the publication of the StaR Child Health Standards (and prior to the development of a number of international paediatric trials initiatives to improve infrastructure and research capacity in child health),${ }^{10}$ it is reasonable to speculate that research published today would be more completely reported compared with what we have presented. Nevertheless,

\begin{tabular}{|c|c|}
\hline Characteristic & n (\%) \\
\hline \multicolumn{2}{|l|}{ Sample size } \\
\hline Calculation reported & $155(51.7)$ \\
\hline Recruitment target reached* & $102 / 145(70.3)$ \\
\hline \multicolumn{2}{|l|}{ Recruitment delays reported } \\
\hline Yes & $19(6.3)$ \\
\hline No & $281(93.7)$ \\
\hline \multicolumn{2}{|l|}{ Types of recruitment delays $\dagger$} \\
\hline Patient-level factors & 10/19 (52.6) \\
\hline Trial-level factors & $9 / 19(47.4)$ \\
\hline Site-level factors & $1 / 19(5.3)$ \\
\hline Trial-team-level factors & $1 / 19(5.3)$ \\
\hline Not specified & 4/19 (21.1) \\
\hline \multicolumn{2}{|l|}{ How recruitment delays were addressed $\neq$} \\
\hline $\begin{array}{l}\text { Stopping the trial before reaching the } \\
\text { target }\end{array}$ & $13 / 19(68.4)$ \\
\hline Extending the recruitment period & $3 / 19(15.8)$ \\
\hline Modifying the eligibility criteria & 3/19 (15.8) \\
\hline Adding additional trial sites & 2/19 (10.5) \\
\hline Modifying incentives & $1 / 19(5.3)$ \\
\hline
\end{tabular}

*Based on sample size calculation and number randomised; data for this calculation were unavailable for 10 trials that reported a sample size calculation.

†Total exceeds 19 because some trials reported more than one type of delay.

$\ddagger$ Total exceeds 19 because some trials reported more than one method. 
reporting shortcomings likely remain and ongoing evaluation of the state of the research will be needed to inform areas in particular need for improvement.

Despite being widely accepted as a requirement, ${ }^{11} 22$ there remains ambiguity about what constitutes assent in paediatric trials, ${ }^{23}$ which children are capable of providing it ${ }^{23}$ and how it should be reported.$^{24}$ Recently, Tait and Geisser established an operational definition of assent, including recommendations about the level of information appropriate for different ages. ${ }^{25}$ Nevertheless, guidance on the age at which children must provide assent varies substantially by country. ${ }^{26-28}$ It also remains unclear whether the level of detail regarding consent and recruitment procedures required by research ethics boards is appropriate or necessary in published reports of paediatric trials. In 2010, Saint-Raymond et al called attention to the need for reporting guidelines specific to research with children. ${ }^{24}$ The development of paediatric adaptations of the Standard Protocol Items: Recommendations for Interventional Trials ${ }^{29}$ and Consolidated Standards of Reporting Trials ${ }^{30}$ statements is under way. ${ }^{31}$

Fewer than $20 \%$ of trials reported who approached families to participate. Although a relationship to the person obtaining consent can encourage recruitment, ${ }^{32}$ when the person is the child's healthcare provider parents may worry that refusing participation will impact their child's quality of care. ${ }^{23}$ In most trials of schoolaged children, trial information was directed to both parents and children. Parents and children's understanding of trial materials are fundamental to ethical and efficient recruitment. ${ }^{3}$ Not understanding trial information discourages parents and children from enrolling in trials, ${ }^{32}$ and some presentations of the benefits and risks of trial participation (eg, as dense text documents) can be difficult for parents to understand. ${ }^{33}$ The integrated consent model in which clinicians engage the trial participant in a consent conversation similar to usual care and additionally present the opportunity for the randomisation of previously validated treatment options has been proposed. ${ }^{34}$ This approach has been suggested for low-risk and pragmatic trials, ${ }^{34}$ however the applicability to paediatric trials needs to be established.

Few trials reported whether incentives were used, but of those that did, many were intended for children. Trial participation can be costly for families, and there is general consensus that they should be reimbursed for the related expenses (eg, travel, parking) at a rate that is sufficient but does not lead them to undervalue risks or coerce them to consent. ${ }^{22}{ }^{32}$ As children value incentives differently than adults, their provision to minors is controversial. ${ }^{3}{ }^{10}$ When incentives are used, it is critical that children understand the implications of the trial and that the incentives do not influence their decision to participate. ${ }^{3}{ }^{10}$ As mentioned previously, allowable payment incentives for children who participate in trials vary by region. As expected, just $4 \%$ of studies that recruited in Europe reported providing incentives, all of which were in the form of compensation. Conversely,
$28 \%$ of studies that recruited in North America reported providing incentives, and $21 \%$ of these were in the form of payments. Given the poor reporting of incentive use, it was not possible to conclude whether offering incentives improved the chance of attaining the recruitment target. Nevertheless, from the few studies that reported whether or not incentives were used, it did not appear that this was the case.

Seventy per cent of trials met their recruitment targets. This is substantially greater than the $29 \%$ reported in St-Louis et al's review of paediatric general surgical trials, ${ }^{35}$ and the $55 \%$ in Sully et als review of multicentre trials in the UK. ${ }^{36}$ Failing to meet the recruitment target contributes to research waste when the trial is underpowered to detect clinically important differences. ${ }^{37}$ Due to reporting deficiencies, we could only ascertain whether trials achieved their recruitment targets for half of the sample. Whether transparent reporting is biased towards trials that meet their recruitment targets is not yet known.

\section{Strengths and limitations}

We have highlighted a number of conduct and/or reporting gaps in an effort to contribute to the ongoing research agenda. Our sample will serve as a baseline for ongoing monitoring of consent and recruitment procedures in paediatric trials. The extracted data were limited to those available within published reports, therefore we cannot ascertain the extent to which the findings reflect conduct and/or reporting shortcomings. Because the sample included studies that reported on participants aged 0-21 years and from countries that varied by income, the sample was highly heterogeneous (ie, consent procedures are different for infants compared with adolescents and young adults, and are highly influenced by cultural norms and local ethical standards) limiting generalisability to specific age groups or regions by income level. Further investigation into trials examining participants in more discrete age groups (eg, infants, young children, adolescents) and in regions of a specific income level (eg, low income, middle income) would be of interest. As we used a sample of trials published in 2012, the findings may not be generalisable to other years.

\section{CONCLUSIONS}

In our sample, five reporting shortcomings were evident: how families were recruited, who obtained consent and/ or assent and how, who trial information was directed to, whether incentives were used and sufficient data to determine if the recruitment target was met. Forthcoming reporting guidance specific to paediatric trials, ${ }^{31}$ and the StaR Child Health Standards ${ }^{3}$ may contribute to improving the conduct and reporting of paediatric trials in this priority area. Using this study as a baseline, continued monitoring of the state of the research will allow for the identification of changes over time and the need for the translation of evidence-based standards into forms that are appealing and accessible to trialists. 
Author affiliations

${ }^{1}$ Alberta Research Centre for Health Evidence, University of Alberta, Edmonton, Alberta, Canada

${ }^{2}$ Department of Pediatrics, University of Alberta, Edmonton, Alberta, Canada

${ }^{3}$ Discipline of Child and Adolescent Health and Centre for Kidney Research, The University of Sydney, Sydney, New South Wales, Australia

${ }^{4}$ Department of Medicine, University of the Philippines, Manila, Philippines

${ }^{5}$ Instituto de Medicina Molecular, Faculdade de Medicina, Universidade de Lisboa,

Lisboa, Portugal

${ }^{6}$ Department of Pediatrics, Hospital de Santa Maria, Centro Hospitalar Lisboa Norte, Lisboa, Portugal

${ }^{7}$ Department of Pediatrics and Child Health, University of Manitoba, Winnipeg, Manitoba, Canada

${ }^{8}$ Clinical Trials Platform, George and Fay Yee Centre for Healthcare Innovation, Winnipeg, Manitoba, Canada

${ }^{9}$ Developmental Medicine, Royal Children's Hospital, Melbourne, Victoria, Australia ${ }^{10}$ Department of Pediatrics, University of Melbourne, Melbourne, Victoria, Australia

${ }^{11}$ Clinical Sciences, Murdoch Children's Research Institute, Melbourne, Victoria, Australia

${ }^{12}$ Institute of Psychology, Health and Society, University of Liverpool, Liverpool, UK

Acknowledgements We thank Robin Featherstone (MLIS, University of Alberta, Edmonton, Canada) for running the search and Sarah Bryson, Huiru Dong, Aimee Gonzalez, Hamza Jafri, Karandeep Jassal, Megan Nuspl, Kassi Shave, Jocelyn Shulhan, and Jaskiran Sidhu (research assistants at the Alberta Research Centre for Health Evidence, University of Alberta, Edmonton, Canada) for contributing to data extraction.

Contributors MPD conceptualised the study, designed the data collection instrument, supervised all aspects of the work, verified and analysed the extracted data, and contributed to drafting the manuscript. AG verified and analysed the extracted data, contributed to drafting the manuscript and completed revisions of the manuscript drafts following input from the other authors. PC, SC, LD, LH, LEK, RMF, KWi and KWo contributed to the interpretation of the extracted data and revised manuscript drafts critically for important intellectual content. All authors approved the final manuscript as submitted and agree to be accountable for all aspects of the work.

Funding This research was funded by the Canadian Institutes of Health Research (\#KRS 140989).

Disclaimer The funder played no role in the design and conduct of the study; the collection, management, analysis and interpretation of the data; the preparation, review or approval of the manuscript; or the decision to submit the manuscript for publication.

Competing interests None declared.

Patient consent Not required.

Provenance and peer review Not commissioned; externally peer reviewed.

Data sharing statement The data collected and analysed from trials included in this study will be available to researchers via reasonable request from the corresponding author. The data will be available immediately following, and for 5 years after article publication. Our data extraction guide is available as a supplementary file.

Open access This is an open access article distributed in accordance with the Creative Commons Attribution Non Commercial (CC BY-NC 4.0) license, which permits others to distribute, remix, adapt, build upon this work non-commercially, and license their derivative works on different terms, provided the original work is properly cited, appropriate credit is given, any changes made indicated, and the use is non-commercial. See: http://creativecommons.org/licenses/by-nc/4.0/.

\section{REFERENCES}

1. Wittmeier KD, Craig J, Klassen TP, et al. The mission of StaR Child Health is to improve the quality of the design, conduct, and reporting of pediatric clinical research by promoting the use of modern research standards. Introduction. Pediatrics 2012;129:S111.

2. Hartling L, Wittmeier KD, Caldwell $P$, et al. StaR child health: developing evidence-based guidance for the design, conduct, and reporting of pediatric trials. Pediatrics 2012;129:S112-7.

3. Caldwell PH, Dans L, de Vries MC, et al. Standard 1: consent and recruitment. Pediatrics 2012;129:S118-23.
4. Ellenberg S, Fernandes RM, Saloojee H, et al. Standard 3: data monitoring committees. Pediatrics 2012;129:S132-7.

5. Hartling L, Hamm M, Klassen T, et al. Standard 2: containing risk of bias. Pediatrics 2012;129:S124-31.

6. Sinha IP, Altman DG, Beresford MW, et al. Standard 5: selection, measurement, and reporting of outcomes in clinical trials in children. Pediatrics 2012;129:S146-52.

7. van der Tweel I, Askie L, Vandermeer B, et al. Standard 4: determining adequate sample sizes. Pediatrics 2012;129:S138-45.

8. Williams K, Thomson D, Seto I, et al. Standard 6: age groups for pediatric trials. Pediatrics 2012;129:S153-60.

9. Gates A, Hartling L, Vandermeer B, et al. The conduct and reporting of child health research: an analysis of randomized controlled trials published in 2012 and evaluation of change over 5 years. J Pediatr 2018;193:237-44.

10. Joseph PD, Craig JC, Caldwell PH. Clinical trials in children. $B r J$ Clin Pharmacol 2015;79:357-69.

11. Graham A, Powell M, Taylor N, et al. Ethical research involving children: putting the evidence into practice. Family Matters 2015;96:23-8.

12. Ioannidis JP, Greenland S, Hlatky MA, et al. Increasing value and reducing waste in research design, conduct, and analysis. Lancet 2014;383:166-75.

13. Glasziou P, Altman DG, Bossuyt P, et al. Reducing waste from incomplete or unusable reports of biomedical research. Lancet 2014;383:267-76.

14. Nayak BK. Understanding the relevance of sample size calculation Indian J Ophthalmol 2010;58:469.

15. Hamm MP, Hartling L, Milne A, et al. A descriptive analysis of a representative sample of pediatric randomized controlled trials published in 2007. BMC Pediatr 2010;10:96.

16. Cochrane. Cochrane Central Register of Controlled Trials (CENTRAL). 2018. London, United Kingdom: Cochrane.

17. Thomson D, Hartling L, Cohen E, et al. Controlled trials in children: quantity, methodological quality and descriptive characteristics of pediatric controlled trials published 1948-2006. PLoS One 2010;5:e13106

18. Harris PA, Taylor R, Thielke R, et al. Research electronic data capture (REDCap)-a metadata-driven methodology and workflow process for providing translational research informatics support. J Biomed Inform 2009;42:377-81.

19. World Health Organization. Classifications. International Classification of Diseases (ICD). ICD-10 online versions. Geneva, Switzerland: World Health Organization, 2018.

20. The World Bank. World Bank Country and Lending Groups. Washington, District of Columbia: The World Bank, 2018.

21. Kaur G, Smyth RL, Williamson P. Developing a survey of barriers and facilitators to recruitment in randomized controlled trials. Trials 2012;13:218.

22. World Medical Association. World Medical Association Declaration of Helsinki: ethical principles for medical research involving human subjects. JAMA 2013;310:2191-4.

23. Leibson $\mathrm{T}$, Koren $\mathrm{G}$. Informed consent in pediatric research. Paediatr Drugs 2015;17:5-11.

24. Saint-Raymond A, Hill S, Martines J, et al. CONSORT 2010. Lancet 2010;376:229-30.

25. Tait AR, Geisser ME. Development of a consensus operational definition of child assent for research. BMC Med Ethics 2017;18:41.

26. Shaddy RE, Denne SC. Committee on Drugs and Committee on Pediatric Research. Clinical report-guidelines for the ethical conduct of studies to evaluate drugs in pediatric populations. Pediatrics 2010;125:850-60.

27. Lepola P, Needham A, Mendum J, et al. Informed consent for paediatric clinical trials in Europe. Arch Dis Child 2016;101:1017-25.

28 Canadian Paediatric Society. Ethical issues in health research in children. Paediatr Child Health 2008;13:707-12.

29. Chan AW, Tetzlaff JM, Altman DG, et al. SPIRIT 2013 statement: defining standard protocol items for clinical trials. Ann Intern Med 2013;158:200-7.

30. Schulz KF, Altman DG, Moher D. CONSORT Group. CONSORT 2010 Statement: updated guidelines for reporting parallel group randomised trials. Trials 2010;11:32.

31. Clyburne-Sherin AV, Thurairajah P, Kapadia MZ, et al. Recommendations and evidence for reporting items in pediatric clinical trial protocols and reports: two systematic reviews. Trials 2015;16:417.

32. Tromp K, Zwaan CM, van de Vathorst S. Motivations of children and their parents to participate in drug research: a systematic review. Eur $J$ Pediatr 2016;175:599-12. 
33. Tait AR, Voepel-Lewis T, Zikmund-Fisher BJ, et al. Presenting research risks and benefits to parents: does format matter? Anesth Analg 2010;111:718-23.

34. Kim SY, Miller FG. Informed consent for pragmatic trials-the integrated consent model. N Engl J Med 2014;370:769-72.

35. St-Louis E, Oosenbrug M, Landry T, et al. Enrollment and reporting practices in pediatric general surgical randomized clinical trials:
A systematic review and observational analysis. J Pediatr Surg 2018:53:879-84.

36. Sully BG, Julious SA, Nicholl J. A reinvestigation of recruitment to randomised, controlled, multicenter trials: a review of trials funded by two UK funding agencies. Trials 2013;14:166.

37. Al-Shahi Salman R, Beller E, Kagan J, et al. Increasing value and reducing waste in biomedical research regulation and management. Lancet 2014;383:176-85. 